\title{
Sexy thrills: undressing the erotic thriller
}

Nina K. Martin; University of Illinois Press, Urbana \& Chicago, 2007, 206p,

ISBN 978-0-252-03195-3, \$65; ISBN 978-0-252-007437-0, \$20

Peter Lehman's back-cover praise for Nina K. Martin's Sexy Thrills: Undressing the Erotic Thriller is rather misleading. He positions Martin's study as 'the first book to fully address and explore the major genre development in cinema commonly referred to as the erotic thriller'. Not only is Martin's study not the first (Linda Ruth Williams' The Erotic Thriller in Contemporary Cinema was published in 2005), it is not a study about cinema. Rather, Martin's concern is with the direct-tovideo (DTV) erotic thriller, and her book provides an overview in order to argue that it can be read 'as an example of a women's genre' (p. 8).

Reading DTV erotic thrillers - a genre perhaps best known for the sexual display of its female stars - as a 'women's genre' is clearly contentious. Martin makes her case in the first chapter primarily through identifying common textual features across a range of films, noting their borrowings of the conventions of romance and melodrama, their almost exclusive emphasis on a female protagonist and (drawing on the other Linda Williams) their feminizing of desire through a focus on the surface of the body in opposition to hard-core pornography's fascination with its depths. However, to a great extent we are asked to take Martin's argument that this is a woman's genre on faith, as she provides no empirical evidence that filmmakers and distributors target a female audience, or that women consume these products in significant numbers. Moreover, her analysis of the films themselves - while lively and engaging - conveniently sidelines the conventional pleasures on offer for the heterosexual male spectator. Indeed, in her more detailed and nuanced account of the genre, Linda Ruth Williams creates a somewhat opposed picture, arguing that the target audience is a heterosexual male one, though she too is interested in the ancillary female audience and the pleasures the genre may offer for them. Williams' greater evidence base (she draws on interviews with industry personnel and makes use of audience reviews, as well as detailed textual analyses of both the films and their promotional materials) makes her argument the more convincing one.

The remaining four chapters of Sexy Thrills develop Martin's initial arguments through a consideration of sub-generic categories within the DTV erotic thriller that, variously, position these films in relation to sex education, film noir and the Gothic, therapeutic discourse and surveillance. In mapping the genre in this way, Martin becomes rather bogged down in the minutiae of (sub)generic classification, and risks losing sight of the bigger picture. In the chapter on instructional discourses, for instance, the thriller in erotic thriller largely disappears from view, although this generic identity must surely impact the 
'lessons' these films offer. The significance of individual sub-generic categories is difficult to ascertain, as Martin does not discuss how these categories relate to one another in the history of the genre (do they run alongside one another or represent shifts or developments over time?); whether they are understood by filmmakers and audiences (is 'the talk show thriller' a marketable category or simply a critical one?); or just how significant they are in terms of profitability and reach (which 'erotic thrillers' are the most profitable and why?). That Martin frames her study with introductory and concluding chapters focused on television is puzzling, given her interest in cinematic connections elsewhere, and suggests something of the rather confusing lineage the book traces for the DTV erotic thriller.

The conclusion also introduces the hitherto neglected question of female authorship, translated over from film studies, with little attention to the specific ways in which questions of authorship may be complicated in television. Female authorship is an interesting line of enquiry vis-à-vis erotic representation, but there is not the space to fully develop this here, and it feels like an afterthought. Indeed, Martin's book itself demonstrates that it is not only on television that female directors have taken on the erotic thriller. With some directors (such as Donna Deitch) able to cite both the DTV erotic thriller and near-canonical films within feminist film studies on their CVs, it would have been interesting to explore the questions of female authorship and women's place within the industry more generally. Instead, the conclusion leaves more questions than it offers answers: what has women's involvement been in the development of the genre (as filmmakers, audience members, stars) and does this significantly shape the possibilities for its representation of desire? If the DTV erotic thriller was - as Martin argues - a product of the 1990s, then what has happened to the genre since: has it transmuted, disappeared or (as her framing perhaps implies) shifted platforms? Greater attention to these questions and to the social context in which these films emerge would have made this a more rounded book of interest not only to scholars/fans of the DTV erotic thriller, but also to genre theorists and feminist cultural historians. At present, it lacks that broader appeal, and while Martin sees the DTV erotic thriller as concurrent with certain developments in popular feminism (or 'do me' feminism), the social and political ramifications of this remain rather under-explored.

\section{reference}

Karen Boyle

Williams, L.R. (2005) The Erotic Thriller in Contemporary Cinema, Edinburgh: University of Edinburgh Press.

doi: $10.1057 /$ fr. 2009.9 